\title{
Exploring Information Technology's Adoption in Restaurants
}

\author{
Chieh-Heng Ko \\ Department of Hospitality Management, College of Tourism and Hospitality, Da-Yeh University, Taiwan \\ Email: chko@mail.dyu.edu.tw
}

How to cite this paper: Ko, C.-H. (2020) Exploring Information Technology's Adoption in Restaurants. Open Access Library Journal, 7: e6470.

https://doi.org/10.4236/oalib.1106470

Received: May 27, 2020

Accepted: June 21, 2020

Published: June 24, 2020

Copyright $\odot 2020$ by author(s) and Open Access Library Inc.

This work is licensed under the Creative Commons Attribution International License (CC BY 4.0).

http://creativecommons.org/licenses/by/4.0/

\section{(c) (i) Open Access}

\begin{abstract}
The purpose of the paper is to explore and compare the current use of information technology-related advances in chain and independent full-service restaurants, the factors that motivate managers of these types of restaurants to decide whether or not to implement such technology, and how these managers perceive the impact of technology on the firm. A case study analysis involving four northern Taiwan full-service restaurants was conducted to examine the framework of full-service restaurants to implement new technology. Propositions are developed that purport the information technology adoption and implementation characteristics of full-service restaurant firms while elucidating the distinctiveness between chain and independent firms.
\end{abstract}

\section{Subject Areas}

Information Technologies

\section{Keywords}

Information Technology Trends, Full-Service Chain Restaurants, Full-Service Independent Restaurants, Entrepreneurship, Technology Leadership

\section{Introduction}

Most systems and processes in this information technology (IT) driven era have some form of hi-tech interface in transforming inputs to outputs. The restaurant industry is no different, in that IT has played some role in changing a customer's dining experience over the years-the way in which the meal is prepared, the speed at which it is delivered, the way an order is received, just to name a few. With the advent of new technology and its impact on restaurant operations, one would believe that most firms in the restaurant industry would be IT oriented in 
the production and delivery of goods and services. Yet researchers have posited that, by and large, the hospitality industry is not technology oriented [1] [2].

While IT clearly presents opportunities for restaurant firms, what remains obscure is decisions related to restaurant firms' (independents and chains) adoption and implementation of new technology. It would also be useful in exploring the difference between chain and independent restaurants in their orientation towards adoption and implementation of new technology, which to date has not been explored by researchers. Based on this, the purpose of this study is to examine how managers and/or owners decide to implement IT in full-service restaurants, and to see what, if any, effects IT could have on the operations of these firms. We do so by studying four restaurant firms using a case study method. It should be noted that while IT adoption and implementation will be studied from the perspective of the four firms, this study attempts to lay the foundation on which future research that entails hypotheses testing could be launched.

Specifically, the study will address three questions: 1) How do full-service restaurant operators generally view the impact of IT? 2) Is there a difference between full-service chain and independent restaurant firms in the adoption, utilization, and implementation of such technology? 3) What are the reasons some chain and/or independent restaurant firms choose not to invest in IT, while others do and what are the implications? The paper first explores why technology matters and the IT-related trends in the restaurant industry followed by a description of the case study approach and the methodology were used in this study. Findings from the restaurants used in the case study ensue, followed by propositions, implications and recommendations while ending with limitations and conclusions. Before exploring each topic, it is essential to state that technology in this paper is referred to as IT, which is defined as "the development, installation, and implementation of computer systems and applications".

\section{Literature Review}

Before exploring IT-related trends in the restaurant industry, it is essential to point out that the authors base the research enquiry on the premise that IT does make a difference [3] and has an impact on firms' performance [4]. This is purported by Ansel and Dyer [5], who concluded that IT use in restaurants could provide four benefits: minimization of costs, better management of employees, revenue management and most importantly, a competitive advantage, and ability to analyze customer preferences and tailor menus towards specific costs. Liddle [6] believes that by 2010 , more than $50 \%$ of changes that will reshape food service will involve technology. These changes will allow restaurants to use technology to control costs, enhance effective management techniques, and allow operators to more closely monitor profit/loss mechanisms in real time, as opposed to waiting until the end of the week, month, etc. Recent trends that depict the impact of IT on restaurant firms are described below.

Customer feed-back mechanisms. Industry trends indicate that specific areas 
being targeted by some restaurants firms include aggressive solicitation of feedback from customers regarding perception of restaurant performance. To some extent, "comment cards" and "mystery shoppers" are being slowly replaced by customer tracking tools which measure the needs of all customers [3]. Such a process includes analysis of online surveys completed by restaurant customers [6]. Real-time guest satisfaction reports and e-mail alerts to corporate management when problems arise are being used as tools to manage restaurant firms. This has improved the service transaction in reducing the response time to solve customer problems [6]. Through technology-based solutions, firms have begun to use web-based as well as in-store kiosks for customer feedback [7]. According to Liddle, this process has generated hundreds of responses per store, and allows restaurant firms to adjust menu offerings, building designs and operational procedures. The customer feedback is then analyzed using computer software (e.g., Customer Relations Management-CRM) [8].

Management of repeat business. Another area targeted by restaurants for innovation through IT is the attempt to increase repeat business. One such area is the use of online reservation systems [9]. Companies such as MICROS Systems Inc. and OpenTable.com provide software that allows clients to offer diners the ability to make online reservations, though not in real time. Some operators report that $30 \%$ of their restaurant's reservations are made via the Internet [9]. Some restaurants have started to use Dotcom companies that provide web-based service to develop a flexible pricing program for off-peak hours, in addition to online reservations and (for a fee to the diner) reservations during peak hours. For a monthly subscription, such firms keep menus of clients' restaurants on a mini-website featuring the client, and automatically lower prices during traditionally off-peak hours or whatever other times the client requests. One such provider reports that restaurant companies who participate in the flexible-pricing program see an average increase of nearly 400 customers a year [10].

Management of marketing and service. Closely connected to frequent diner programs are advances in IT that allow restaurants to gather and store specific information about its customers, which comes mostly from comment cards/online surveys and POS data [11]. By knowing customers' likes and dislikes and their consumption patterns, firms are able to position their product/service offerings more effectively while being able to offer them special deals. Another area that restaurants look at when trying to improve performance is the speed of service. Restaurant firms, both chains and independents, have started to use handheld devices that allow servers to remotely notify management of a dirty table, so that it can be cleaned and re-set faster for another set of patrons as well as place orders in the kitchen [8]. Such technology has helped restaurant operations in activities such as placing orders remotely without having to walk to an ordering terminal, and allowing staff to alert management that a table is now empty [11]. In fact, the most potent application of IT is to use it to support more personalized service; such processes can reduce time related to 
service functions and provide more consistency and accuracy than the most conscientious and skilled human beings [12]. Although service providers add warmth, sensitivity, and a smile to the service, they can lead the customer through technology-based steps in the service process and still provide them with friendly service with a personal touch to make them feel welcome while increasing satisfaction.

IT and restaurant operations management. The use of technology to improve performance can be seen in use of integrated business solution software to help run restaurants operations. Until recently, restaurants were forced to use multiple software programs to help with operations-there was one software package to process payroll, one for inventory management, another to run Point of Service, and still another to process accounting functions such as Accounts Receivable and Accounts Payable. New technology has assisted in the development of an integrated software package that can run all functions on a single platform. Solutions such as remote hosting of Point of Sale systems are also provided by Application Service Providers (ASPs) [13] that restaurant firms could implement for managing operations. Some reports suggest that ASP applications lead to savings ranging from $\$ 10,000$ to $\$ 20,000$ by allowing store managers to view sales and labor reports in real time [13].

Some software companies provide solutions that aid with labor, inventory and food costs, profit and loss management and sales forecasting [14]. Such solutions help in menu engineering and analysis that integrate well with other systems, such as POS and accounting functions [14] as well as Restaurant Revenue Management (RRM) to boost sales [15].

Human resources management. Restaurant firms have begun to provide outsourced workforce management solution software to help restaurants train current staff members and provide workforce selection and optimization tools [6]. Providers have developed job-specific employee selection modules, which focuses on such aspects as personality traits and skills needed for managerial, front-of-house and back-of-house positions to help managers hire the right people for the job (Peoplereport.com; Unicru.com). Solutions for Human Resource Management (HRM) are also technology based that fully integrate with payroll, reporting and analytical decision-making tools, plus a central Web portal that serves as a gateway to company-related activities, and allows staff and management to access critical information quickly and perform routine business activities more efficiently (Ultimatesoftware.com). The effect that HRM can have on a firm's success is well documented in the extant literature [16]. Through technology-based HRM systems, operators could manage employee behavior and the work environment more effectively in order to control turnover and related costs.

"Back-of-the-house" management. Restaurants are also turning to technological advances in the back-of-the-house equipment they use for everyday operation that include linking a wide range of food preparation equipment, such as 
freezers, chillers, ovens and fryers and enabling them to talk the same "language" [17]. If, for example, a restaurant decides to change and/or add a menu item, instructions can be sent to a restaurant via a PC, which will then "talk" to the oven or a deep fryer to automatically change the temperature, so as to prevent overcooking of menu items. The cumulative effect is that labor, food and operating costs are lowered. Other advances in technology include solutions that increase the efficiency of the ventilation system [17], as well as monitoring the wear and tear of equipment while identifying preventive maintenance schedule on a timely basis [14].

In summary, studies have shown that some of the tangible benefits that may be achieved are minimization of costs (such as food, labor, beverage and energy), better employee management techniques, increased revenue management, and the ability to analyze customer preferences, with benefits achieved through the use of computer software packages or through outsourcing services to other firms. This review provides a benchmark for comparing the firms used in the case study to new IT-related technological developments within the industry. The use of new technology reported in this section is not common, rather only few firms have invested in such technologies. To know why some firms invest in new technology while others do not, it is essential to explore the decisions pertaining to investment in new technology of firms. The following section reports the methodology used in this study.

\section{Methodology}

\subsection{Case Study Method}

In order to conduct a more thorough investigation of how full-service restaurants implement new technology, it is essential to gather data from restaurant operators themselves to learn about their goals and understand how they perceive the impact of IT. A better way to conduct such research is through the exploratory method of investigation involving a case study method, which is supported by Darke et al. [18], who refer to case studies as the most appropriate form of research methodology in the study of information systems' application in the organizational context. In fact, a case study allows to capture and document knowledge and experiences of industry practitioners [19]. Since the purpose is to study the perceived impacts and investment/implementation decisions related to technology, a case study method is better suited for this study. While there are weaknesses associated with the case study method (e.g., response bias, interviewer bias, generalizability, etc.), scholars such as Yin [20] have supported the use of the case study method.

\subsection{Questionnaire Development and Sample Description}

In order to gather information about the firms included in the study, a questionnaire was developed using information based on current and future IT-related industry trends as reported in the previous section. The questionnaire 
was used as a framework to explore the adoption and implementation decisions during the interviews with managers. The questions were designed to assess views on important aspects related to the impact/use of technology in general, and specifically in the following areas: staff training, customer profiling/guest tracking, customer retention programs, advertising, marketing, online reservations, managing food and labor costs, management of inventory, payroll management and accounts payable/receivable, menu analysis, food ordering automation services, guest comments and credit-card processing.

As detailed in Table 1, four full-service restaurant firms were chosen for the case study. The independent restaurants 1 and 2 represent firms with single owners, i.e., Mr. Huang and Mr. Chen, respectively. Note that the names used to refer to the restaurant owners/managers of all four firms are fictitious to maintain the confidentiality of the interviewees. They have complete control over operations, but with limited resources to allocate as compared to the chain restaurants. Conversely, Firms 3 and 4 represent firms with the financial backing of a corporation, but having store managers (Mr. Lee and Mr. Chao) with limited decision-making capabilities. It should be noted that the Director of IT (Mr. Tsai) for Firm 3, who has more control over the decisions to implement new technology, was also interviewed to obtain a better perspective of the technology adoption and implementation decisions.

The four firms also differ in the level of control they have on day-to-day operations and management; Firms 1 and 2 have absolute control over the food and drink menu, décor, ordering of supplies and equipment, hiring decisions, etc., while Firm 3 gets practically all direction from the corporate office, with hiring decisions as the only exception and Firm 4 has a mix of decision-making capabilities and receiving direction from its corporate office. Given the differences between the firms, it will be interesting to study how each of these firms value the importance/impact of IT.

Table 1. Characteristics of case study restaurants.

\begin{tabular}{|c|c|c|c|c|}
\hline & Firm 1 & Firm 2 & Firm 3 & Firm 4 \\
\hline Location & $\begin{array}{l}\text { Downtown } \\
\text { Taipei }\end{array}$ & $\begin{array}{c}\text { New Taipei Bay } \\
\text { Area }\end{array}$ & $\begin{array}{c}\text { New Taipei Bay } \\
\text { Area }\end{array}$ & $\begin{array}{c}\text { Taipei Mountain } \\
\text { Area }\end{array}$ \\
\hline Ownership & $\begin{array}{c}\text { Independent } \\
\text { restaurant }\end{array}$ & $\begin{array}{l}\text { Independent } \\
\text { restaurant }\end{array}$ & Chain restaurant & Chain restaurant \\
\hline No. of units & 1 & 1 & 21 & 15 \\
\hline Segment & Full service & Full service & Full service & Full service \\
\hline No. of seats & 60 & 144 & 250 & 132 \\
\hline Market positioning & Upscale & Upscale & Mid-scale & Mid-scale \\
\hline $\begin{array}{c}\text { No. of } \\
\text { employees/managers }\end{array}$ & $12 / 3$ & $24 / 4$ & $58 / 5$ & $30 / 3$ \\
\hline
\end{tabular}




\section{Results}

\subsection{Firm 1}

With regard to the use of technology, Mr. Huang views financial resources as scarce. He does find it useful in some areas; for example, he uses a software package called Squirrel Software for most front-of-house operations. This package acts as a POS system and automates the process of food ordering; a member of the wait staff enters the customer's order by using a "touch screen" which then prints the food order to the kitchen in the back and the beverage order to the bar area in the front. The Squirrel software package also provides a program which tracks employee attendance, aiding with the processing of payroll (completed by a local bank). He also uses a software package for processing credit-card purchases. For back-of-house operations, he uses a software package from Microsoft which helps with inventory and food cost management and labor scheduling; he is fully aware of the fact that any reduction in costs will help his bottom line. However, for the most part, Mr. Huang tends to stay away from IT use. He does not use any form of technology to train his staff, he prefers to train them one-on-one and with a video or $\mathrm{CD}$. He also does not use IT to attempt to increase revenues; he neither sees the value in marketing ideas like coupons, frequent diner programs or other similar programs, nor any value in investing in a company website. He neither believes in the value of advertising with print (newspapers, magazines) and electronic media (Internet, etc.), nor does he have interest in ensuring participation in restaurant surveys. He also has no interest in developing partnerships of any kind. Since $75 \%$ of his business is from repeat customers, he believes "word-of-mouth" is the best form of advertisement; "if a customer has a problem with their experience, I prefer to deal with it right away, instead of having them fill out a comment card. If I don't fix it right away, they might not come back, and my business will be forever harmed."

In summary, Mr. Huang said that he sees some value when investing in technology, especially technology like touch-screen food-ordering system, which helps make the behind-the-scene part of his job easier, as well the job of his food servers easier so they can spend more time with the customers. However, for the most part he does not feel the need to utilize much technology in his firm. He indicated that he spends approximately US $\$ 5000$ annually on any type of technology, which includes both purchasing/leasing new equipment as well as repairing existing equipment. In addition, he prefers a payback of 2 years or less for any investment he makes. He sees little value in investing in technology to aid him in market development; he believes that taking care of the customer by himself is the best thing he can do for his business. "While some technology is helpful, I fear it will take me away from the customer. One-on-one contact is extremely important, I want to be able to look someone in the eye and shake their hand and get to know them. After all, a smile costs nothing and goes a long way to making someone feel comfortable at my place." 


\subsection{Firm 2}

With regard to the use of IT, Mr. Chen's goal is to achieve at least $3 \%$ growth year over year, and he believes that the use of technology can help him achieve those numbers. Approximately $5 \%-10 \%$ of his profits each year are available to be spent on some form of new technology. He currently only uses technology to provide POS software, credit-card processing and payroll management. However, he would be open to using technology in other areas, such as customer profiling, online reservations, labor scheduling and inventory management. Mr. Chen said, "I am all for anything that will allow me to spend less time in the back doing paperwork and allowing me to spend more time on the floor with my customers." Mr. Chen also believes that word-of-mouth is the best way for him to generate new business. Like Mr. Huang, he does not see the value in marketing ideas like coupons, frequent diner programs or other similar programs.

In summary, Mr. Chen said that he sees some value when investing in technology, especially technology described above which helps make the behind-the-scene part of his job easier, as well the job of his food servers easier so they can spend more time with the customers. However, he also said that "While technology is a good thing from time to time, I firmly believe that there is a human element that technology cannot replace, such as greeting a customer and getting to know them. Making customers happy is the name of the game, and you can't always do that with technology. Technology can't help you find out what kind of wine a customer likes or what their favorite meal is, you can only learn that by asking them directly."

\subsection{Firm 3}

In Firm 3, Mr. Lee's level of control and the ability to make changes in the firm is limited. Practically everything is dictated by the corporation-from hours of operation, to menu items, to the design and décor of the restaurant, even down to the uniform styles-it is all set by the corporation and not subject to change. Mr. Lee indicated that all decisions regarding use of IT were made by the corporate office and referred all questions about Firm 2's technology strategy to Mr. Tsai, Director of IT.

Regarding the use/impact of technology, Mr. Lee sees little to no value in using technology to help with advertising and marketing. The Bay Area store neither makes use of coupons, nor does it have any partnerships with local merchants, etc. Mr. Lee believes that firms can get sucked into spending money in marketing, and it does not always work. "I have found over the years that the best form of advertising is through word of mouth from current customers." $\mathrm{He}$ also sees very little value in the use of IT for any type of automated reservation system.

A technology Mr. Lee finds real value is in the use of POS software. While he is pleased with the current POS system they utilize via a company called HSI software, he would like to see the firm upgrade to one that sends the information 
directly into the computer system at corporate headquarters to make the reporting part of his job easier and more efficient. He also sees value in the use of wireless technology for his food servers to use. Currently, food servers utilize touch-screens to place a customer order to the kitchen staff and though he feels the speed of that system is good, he believes that if his staff could place an order to the kitchen from some sort of handheld device, it would allow a customer's order to be served even faster, thus positively adding to the customer's experience. He was careful to mention, however, that he is wary of becoming too reliant on technology. For example, "if the computer system breaks down for a period of time and food orders are lost, I know that customers won't really accept that as an excuse, they just want their food in a timely fashion. If they don't get it, they will go somewhere else-especially since there are a number of dining choices in this shopping center."

As mentioned earlier, Mr. Tsai was identified as the decision maker for possible use of technology within the Firm. He has been with the Firm for 10 years, for the last 7 years in the IT department. Mr. Tsai has been Director of IT for the last 2 years, and is the highest ranking person in IT and reports directly to the Chief Financial Officer. When reviewing IT strategy, Mr. Tsai indicated that they view operations from strictly a corporate point of view. Specific requests from individual store managers are considered, but will not be implemented unless every store can benefit from the product. In addition, all the daily sales information goes straight into a database at the corporate office in Taipei. They also utilize a software package called BI Query which aids Firm 3 in menu analysis. This tool helps analyze trends and forecasts, which they use to determine if certain menu items should be removed from the menu due to lack of customer demand.

When deciding whether or not to implement a new technology product, Mr. Tsai indicated that they break down their analysis into two parts: the project inception phase and the vendor selection phase. In the project inception phase, Mr. Tsai surveys the leaders of all departments, creates a needs assessment list and then creates a list of needs within his own department. Next, senior management gets together and prioritizes the list. Interestingly, they do not separate corporate projects and operational projects; each project is evaluated on its own merits, i.e., the possible Return On Investment (ROI). However, they do not use any formal capital budgeting techniques such as Net Present Value (NPV)-based decision analysis, break-even points or estimated payback periods.

During the vendor selection phase, Mr. Tsai indicated he looks for three things when deciding whom to choose-vendors should be large enough to handle the firm, willing to meet their requirements, and flexible enough to adapt to their systems. Mr. Tsai indicated they are fortunate in that they do not have to worry a lot about costs-the annual budget for IT is approximately $\$ 2$ million for this fiscal year, though he indicated they look to save money where possible and do not buy more than what they need just because they can. The important thing is that they implement projects whenever deemed necessary. In fact, Mr. 
Tsai indicated he is currently talking to two vendors about implementing a wireless technology featuring a handheld device for use by food servers to place food orders remotely. He also mentioned a recent change they made to their system of collecting feedback from guests, moving from comment cards to an Interactive Voice Response (IVR) system. They also have a section on their website which allows for customer comments, with the hope that they will be better equipped to respond to customer requests for improvements to operations.

\subsection{Firm 4}

As described before, Firm 4 is a chain restaurant with 15 locations, with all restaurants owned by the corporation. Regarding the level of control to make changes, Firm 4 differs greatly from Firm 3. Though Mr. Chao is part of a corporation, he has a great degree of control in restaurant operations; he has final say in the restaurant's budgets, as well as its layout and menu items.

Regarding the use of technology, Mr. Chao does believe it has some advantages. Firm 4 does have a vendor of choice-Aloha software-that provides a large number of products for them, such as labor scheduling, payroll management, menu analysis, POS, touch-screen ordering system, guest comments and credit-card processing. In addition, Mr. Chao would be interested in learning more about other technologies, such as more efficient kitchen equipment, wireless technology such as food ordering systems and advertisement automation. He indicated that he must get corporate approval for spending any money on technology driven items, but has found them to be very responsive to his requests. Mr. Chao does not use formal capital budgeting techniques to make decisions pertaining to implementing new technology. Firm 4 also utilizes the Internet to drive business; they currently have a corporate website-customers can sign up via e-mail for weekly menu updates, coupons for free desserts, etc. In addition Mr. Chao is looking at partnering with Google for online searches for local restaurants.

In summary, Mr. Chao's views seem to fall in-between those of his counterparts. On the one hand, he believes-as his peers do-that the customer is the number one priority, and there are some aspects of the business that technology cannot touch; namely, getting to know your customer, learning what they like and do not like first hand, and if there is a mistake, the ability to fix it right away. However, he also believes-more than most of his peers-in the value that technology can bring to the organization now and in the future. While he believes in new technology and its role in restaurant operations and has implemented new technology to some extent, his store still lacks an orientation towards new and recent developments in technology highlighted in Section 3.

\section{Developing Propositions}

Based on the findings, this section analyzes the firms' technology orientation by re-visiting the research questions to provide a perspective of how each firm 
views the issues raised at the outset. First, the firms' view of the impact of IT is explored: do they even see any benefit in implementing any of the available products in their firm? At Firm 1, Mr. Huang stated that he is willing to implement technology if it will make it easier for him to complete the more mundane parts of the job-processing payroll, keeping track of inventory, etc. - so that he could spend more time with his customers and doing whatever he could to improve their experience. He is also willing to look at any technology that will make operations easier for his food servers, so they too could spend more time interacting with the customers, though he certainly indicated there are areas of operation, such as advertising and training, that he has absolutely no interest in implementing technology. Mr. Huang was clear to mention several times that resources available for implementation of technology are very limited. However, it is clear that at least for some areas of operations, he generally sees some value for technology. Mr. Chen and Mr. Tsai indicated that they also see the value of technology. They both are open to considering any technology that will help Firm 3 improve the dining experience of customers.

Firms 1 - 3 have chosen not to invest in technology in areas such as advertising and marketing whereas Firm 4 has made some efforts in this area. As noted earlier, Mr. Huang does not even have a website on the Internet for his restaurant. Even Firms 2 and 3 have not taken significant measures to market/advertise the product using technology or traditional sources, which might be effective in increasing the market share of these firms. Another area that none of the firms chose to invest in IT is in the area of employee training. All four interviewees feel it is important to train employees in their own ways, which is specifically adapted to the needs of their firm. However, training via outsourced technology-such as online methods from an outsourced company who specializes in training-might make their employees better food servers, and would free up their schedule to spend time performing other tasks. This is another example where the consequences of not utilizing IT could be costing the firms from developing their business potential, since none of them is engaged in formal scanning of the environment for updating information on the long-term impacts of IT. This leads to Proposition $1(\mathrm{a}-\mathrm{c})$ :

$P 1(a)$ : Full-service chain restaurants are more likely to implement some form of new IT-related developments faster than full-service independent restaurants.

$P 1(b)$ : To a large extent, both full-service chain and independent restaurants give least priority to investing in new IT related to functional areas outside of operations.

$P 1(c)$ : Full-service independents are more likely to be short-term oriented in how they view the impact of technology.

Next, the utilization of IT was explored. Do these firms currently use technology, and is there a difference between full-service chain and independent restaurants in adopting recent IT-related developments? Firm 1 uses a POS software system, a touch-screen system to place orders to the kitchen and a software package to help with inventory management, credit-card processing, food/beverage 
cost management and labor scheduling. At Firm 3, technology is utilized much more frequently, which is not surprising given the fact they have much more resources than Firms 1, 2, and 4. Firm 4 has not currently utilized IT as much as Firm 3, but they have stated their intent to do so. Firm 3 also utilizes technology in the form of a software package that provides menu analysis and another one that automates the system in which customers can register comments on their dining experience. In fact, Firm 3 very recently switched from a card-based system to an automated telephone system used to gather and analyze customer comments, in the hope that this will give the corporate office some insight on areas that Firm 3 needs to improve in its operations. They also have a section on their website where customers could write or even e-mail them their suggestions and comments.

In contrast, at Firm 1, Mr. Huang indicated that he does not use any sort of system to formally gather guest comments; rather he tries to address a problem before a customer even leaves the restaurant. However, this procedure leaves a lot to chance. There may be times when a customer does not come across as visibly unhappy at the time of leaving the restaurant, but perhaps later on they realize the meal was not quite up to par, the service was too slow, etc. Because there is no system to write, call and/or e-mail with comments, they may simply decide to never return. Thus, the consequences could be lost business for Firm 1 for something that could have been easily prevented. As summarized in the section on technological developments in the restaurant industry, some firms are adopting new IT which, to some extent, reflects the current use of IT in the industry. The IT orientation of all four firms reflects a lack of leadership since they are not current in the utilization of new or recent technology when compared to the trends reported in Section 3. Although Firm 3 has taken some steps towards IT implementation in some operational areas, it is not current in implementing new technology, which also applies to Firm 4. Moreover, to a large extent, barring Firm 4, the other firms did not view new/recent IT trends to impact their firm in a significant way. This reflects a lack of IT leadership on the part of these firms, which leads to Proposition 2 ( $\mathrm{a}$ and $\mathrm{b}$ ):

P2(a): Although full-service independent and chain restaurants will invest in some level of technology, Collectively, the firms demonstrate a lack of IT leadership.

P2(b): Full-service chain restaurants are likely to be more current in the use of technology as compared to full-service independent restaurants, all else being equal.

Finally, the question of the decision to invest is explored: why do some firms choose to invest while others do not, and what are the implications? Mr. Huang and Mr. Chen are small business owners, who could also be referred to as entrepreneurs. Indeed, they would appear to fit the role, as Webster's Dictionary defines an entrepreneur as "a person who organizes and manages a business undertaking, assuming the risk for the sake of the profit” [20]. In fact, Hamel [21] found entrepreneurs are defined as those who are innovators obsessed with 
creating truly revolutionary ideas.

Based on the above definition, it could be stated that Mr. Huang and Mr. Chen appear to fall short of the entrepreneur's role. They state that their goal is to provide a great product and great customer service, but there seems to be a contradiction in their actions. On the one hand, they want to keep their customers happy, but as an entrepreneur, where is the desire to innovate? They invest in technology on a limited basis because of lack of resources. However, perhaps an investment in IT possibly could be a good way to attempt to increase the scope of the firm's operations. He appears to be short-sighted in his view and demonstrates a lack of awareness that IT could have benefits in many different areas, not just the ones he recognizes. He is reluctant to spend money on anything that has a payback period of longer than 2 years. If a payback period on a piece of technology takes longer than 2 years but allows for a sharp increase in returns in the years following the payback period, Mr. Huang would not consider such investments because of his short-term perspective to analyzing investments.

Firms 3 and 4, on the other hand, demonstrated a willingness to invest in the use of technology, as described earlier in this paper. Though they are significantly larger in size than Firms 1 and 2 and consequently have more resources at their disposal, Firms 3 and 4 have recognized the value of IT. As a result, they are better able to keep their stores performing at a high level while investing in front-of-house and back-of-house equipment. They have recognized that investments in the latest kitchen equipment could help ensure it will not break down and interrupt service. In addition, they are able to gather information on customer preferences through software used to analyze daily customer purchases, and determine which customers order more frequently. Further, they use software that allows them to gather information from a website regarding customer suggestions/complaints for improvement.

The managers of Firms 3 and 4 view the impact of new technology to be positive. They are constantly looking for ways to improve their product and services while also improving their bottom line. As compared to Firms 1 and 2, the chain restaurants covered in this study have a good IT implementation process in place as reflected in the vendor selection and technology adoption process. And unlike Firms 1 and 2, Firm 3 has no limit on what the length of payback period should be for a particular investment; they invest in items whenever it is deemed necessary, regardless of how long it takes to recoup expenditures. As a result, it could be stated that Firms 3 and 4 are able to reap benefits that are unavailable to Firms 1 and 2. However, the orientation to technological investments is dependent on how each manager views the impact of technology. Since there is no formal system in place, the extent to which investments in IT will be made would depend on the manager. This leads to Proposition 3 (a-c):

P3(a): Unlike full-service independents, full-service chains are more likely to be more entrepreneurially oriented for IT adoption and implementation than full-service independent restaurants, all else being equal. 
P3(b): The level of entrepreneurial orientation towards IT on the part of full-service chain restaurants will depend on their financial position.

P3(c): Unlike full-service independents, full-service chain restaurants are more likely to use some level of formal technology formulation and implementation processes to adopt new IT. The extent to which such processes will be used would depend on the decision maker's perception.

\section{Implications and Recommendations}

The findings of this study point out that, if indeed the framework used by the independent full-service restaurant owner surveyed in this study reflects the process used by the average full-service independent restaurant in Taiwan, the authors might not be wrong in stating that the average full-service restaurant firm would not be oriented towards incorporating new technology into operations and functional aspects of business until such time that the technology becomes a necessity for survival. This is despite the fact that the results of implementing such technology are discernable ahead of time. It is evident that the absence of initiative on the part of firms included in this study is a function of a lack of entrepreneurial orientation towards IT-related investments. Since our study cannot be generalized, future studies that include samples representing the various facets of the industry should test the technology-related entrepreneurial orientation of restaurant firms. However, it could be stated that if indeed the average full-service firm in Taiwan is owned by an independent owner, this would imply that the industry would remain less technologically oriented in the long term. The fact that researchers are not aware of the technology orientation of independent firms across the various segments of the restaurant industry in itself warrants future efforts that should explore their IT orientation. This has several implications ranging from productivity-related impacts to increased product and service quality and improved customer relationship management that technology offers.

On the other hand, full-service chain restaurants might be relatively more IT oriented when compared to an independent restaurant. However, they are by no means innovative in the true sense of the word. The impact of IT for such firms needs to be studied at two levels, i.e., the corporate and the store level. Managers at the operating level are better off in providing feedback to corporate-level managers regarding the need for new technology and there should be some level of discretion that store-level managers should be provided in order to make a difference regarding utilizing new technology in stores. Corporate managers who are removed from functions at the store-level tend to overlook the real impact of IT despite the comprehensive analysis that might go into the decision-making process. Such processes would be well served if the firm creates a technology team that has a good representation of store managers. For instance, although Firm 3 has demonstrated a liberal use of technology, neither the store manager nor the Director of IT suggested the use of the RRM software to moni- 
tor productivity. Given that prior research [22] [23] has documented the positive impact of such technology on the restaurant firm, the restaurants included in this study could benefit from the use of this technology.

Last but not least, the absence of formal capital budgeting techniques might explain why both independent as well as chain full-service restaurants demonstrate a lack of technology leadership. Capital budgeting techniques would enable these firms to assess the risk of investing in new technology from a value-adding standpoint, which would provide managers a better framework to implement decisions pertaining to technology. Although it could be argued that this finding is specific to the firms included in this study, it should be noted that if this finding is applicable to the average firm in the industry, it would reflect a lack of formal methods of evaluating technology-based investment decisions made by practitioners. This, however, needs to be validated through future research efforts.

Based on the findings of the study pertaining to the four firms, the authors would make the following recommendations to practitioners:

1. Technology orientation is a process and not an outcome. Since IT-based products, services and processes evolve to newer forms because of evolutionary mechanisms, full-service restaurant firms, whether independent or chain, would need to consistently scan for information pertaining to new technology.

2. Differentiate between operational and functional impacts of IT. Technology impacts operations as well as other functions such as marketing (e.g., customer relations, advertising), administration (e.g., purchase, accounting), human resources (e.g., hiring, training), and so forth. Full-service restaurant firms should analyze these impacts so that equal technology emphasis is given to all functions.

3. Analyze financial impacts of IT. Store-level managers ought to know how to: (a) evaluate investments in technology using capital budgeting techniques, and (b) minimize transaction costs through the use of innovative technology.

4. Focus on information management. Technology helps in managing the firm's knowledge resource. Information on markets, products, customers, and transactions needs to be managed effectively, which technology does more efficiently than human beings.

5. Timely implementation of technology. Technology leadership results when firms implement new technology. Just information processing and technology formulation is not enough, implementing the formulated technology strategy through information processing in a timely fashion is essential. This is important given the fact that technology evolves at a very fast rate. Formulation of technology strategy should be followed by in-time technology implementation. Competitive advantage results from technology leadership.

6. Long-term orientation. Technology leadership would also result if full-service restaurant firms are long-term oriented. Short-term orientation would not help the business in terms of evaluating the impact of IT-related investments. Moreover, technology-related decisions are affected in a negative way when firms are short-term oriented. 


\section{Conflicts of Interest}

The author declares no conflicts of interest regarding the publication of this paper.

\section{References}

[1] Siguaw, J.A., Enz, C.A. and Namasivayam, K. (2000) Adoption of Information Technology in US Hotels Strategically Driven Objectives. Journal of Travel Research, 39, 192-201. https://doi.org/10.1177/004728750003900209

[2] Buhalis, D. and Main, H. (1998) Information Technology in Peripheral Small and Medium Hospitality Enterprises: Strategic Analysis and Critical Factors. International Journal of Contemporary Hospitality Management, 10, 198-202. https://doi.org/10.1108/09596119810227811

[3] Hayes, J. (2002) Industry Execs: Best Customer Feedback info Is "Real" Thing. Nation's Restaurant News, 18 March 2002, 36(11).

[4] Devaraj, S. and Kohli, R., (2003) Performance Impacts of Information Technology: Is Actual Usage the Missing Link? Management Science, 49, 273-289. https://doi.org/10.1287/mnsc.49.3.273.12736

[5] Ansel, D. and Dyer, C. (1999) A Framework for Restaurant Information Technology. Cornell Hotel and Restaurant Administration Quarterly, 40, 74-84. https://doi.org/10.1177/001088049904000322

[6] Liddle, A.J. (2002) NRA Tech Poll Bolsters Think-Tank's 2010 Forecast. Nation's Restaurant News, 26 November 2002, 36(47).

[7] Liddle, A.J. (1999) Customer Satisfaction: Technology. Nation's Restaurant News, 13 September 1999, 33(37).

[8] Frumkin, P. (2002) Operators Turn to Technology to Feed Customer-Service Demands. Nation's Restaurant News, 25 November 2002, 36(47).

[9] Ruggless, R. (2003) Industry Execs, Educators Seek Ways to Boost Customer Counts. Nation's Restaurant News, 15 December 2003, 37(50).

[10] Liddle, A.J. (2003) Using Web for Discounting Clicks with Digital Diners. Nation's Restaurant News, May 2003.

[11] Prewitt, M. (2003) Wireless Technology Is the Formula for Better Customer Service. Nation's Restaurant News, November 2003.

[12] Berry, L. (2001) Improve Service by Acting Small. Managing Service Quality, 11, 75-79. https://doi.org/10.1108/09604520110387446

[13] Liddle, A.J. (2001) Walking the Point-of-Sale Tightrope Protected by Unconventional Net. Nation's Restaurant News, 26 February 2001, 35(9).

[14] Nation's Restaurant News (2003) Red Robin Tackles Food, Labor Costs. Nation's Restaurant News, October 2003.

[15] Yin, R. (1994) Case Study Research: Design and Methods. 2nd Edition, Sage Publications, Thousand Oaks.

[16] Koys, D. (2003) How the Achievement of Human-Resources Goals Drives Restaurant Performance. Cornell Hotel and Restaurant Administration Quarterly, 44, No. 1.

[17] Blair, A. (2003) Equipment Learns Common Data Language. Nation's Restaurant News, 37(43), 14.

[18] Darke, P., Shanks, G. and Broadbent, M. (1998) Successfully Completing Case Study Research: Combining Rigour, Relevance and Pragmatism. Information Systems 
Journal, 8, 273-289. https://doi.org/10.1046/j.1365-2575.1998.00040.x

[19] Benbasat, I., Goldstein, D.K. and Mead, M. (1987) The Case Research Strategy in Studies of Information Systems. MIS Quarterly, 23, 369-391.

https://doi.org/10.2307/248684

[20] (1986) Webster's New World Dictionary. 2nd College Edition, Prentice-Hall press, Englewood Cliffs, 467.

[21] Hamel, G. (2001) Bringing Silicon Valley Inside, Crafting and Executing Strategy. 12th Edition, McGraw-Hill Publications, New York, 606-608.

[22] Kimes, S. and Thompson, G. (2004) Restaurant Revenue Management at Chevys: Determining the Best Table Mix. Decision Sciences, 35, 371-392. https://doi.org/10.1111/j.0011-7315.2004.02531.x

[23] Susskind, A., Reynolds, D. and Tsuchiya, E. (2004) An Evaluation of Guests' Preferred Incentives to Shift Time-Variable Demand in Restaurants. Cornell Hotel and Restaurant Administration Quarterly, 45, 68-84.

https://doi.org/10.1177/0010880403260108 